\title{
OVERVIEW OF EROSION MECHANISMS, IMPURITY TRANSPORT, AND DEPOSITION IN TEXTOR AND RELATED MODELING
}

\author{
A. KIRSCHNER* and V. PHILIPPS Institut für Plasmaphysik, Forschungszentrum Jülich GmbH \\ EURATOM Association, Trilateral Euregio Cluster, D-52425 Jülich, Germany
}

M. RUBEL Alfvén Laboratory, Royal Institute of Technology

EURATOM Association, Teknikringen 31, S-10044 Stockholm, Sweden

PH. MERTENS Institut für Plasmaphysik, Forschungszentrum Jülich GmbH EURATOM Association, Trilateral Euregio Cluster, D-52425 Jülich, Germany

TEXTOR TEAM

Received April 29, 2004

Accepted for Publication August 22, 2004

This paper gives an overview of the research activities at TEXTOR on impurity production, impurity transport through the plasma, and then deposition. First, laboratory experiments on chemical erosion by hydrogen and oxygen and radiation-enhanced sublimation are described, followed by the main part, which concentrates on the TEXTOR data of impurity release, impurity transport, and redeposition. The differences between the behavior of high-Z and low-Z materials are discussed. Many of the TEXTOR experiments are carried out using special limiter locks, but the overall carbon balance of net erosion sources and net deposition zones are also shown. Finally, modeling of erosion and dedicated transport experiments are addressed.

KEYWORDS: erosion, impurity transport, deposition

\section{INTRODUCTION}

Plasma-wall interaction is one of the key issues in fusion research. The unavoidable contact of the plasma with the surrounding walls leads to the release of wall material due to erosion. The erosion of wall material can limit the lifetime of plasma-facing components (PFCs) and, even more severe, will lead to the redeposition of

\footnotetext{
*E-mail: A.Kirschner@fz-juelich.de
}

these materials on some wall areas where they can be codeposited with the fuel species, thus resulting in unacceptably high tritium accumulation. Furthermore, the eroded particles can be transported into the core plasma where they cause dilution of the plasma fuel and cool the plasma by radiation. Both effects reduce the effectiveness of fusion processes and, therefore, should be minimized.

High- $\mathrm{Z}$ materials like tungsten have the advantage of reduced or negligible wall erosion due to low physical sputtering rates. However, because of their large atomic numbers, they possess a high potential for radiation cooling. Moreover, the use of metals as wall material in fusion devices can lead to additional erosion by melt layer losses in transient heat loss events such as disruptions or edge-localized modes (ELMs).

Low-Z materials like carbon and beryllium have less potential for radiation cooling but in general have the disadvantage of a high physical sputtering yield, which limits the lifetime of such wall elements. The main advantage of graphite as the first-wall material is that it can withstand extremely high power fluxes without melting. Their main disadvantage is that they suffer from chemical erosion caused by the impact of hydrogen and also oxygen. The large erosion occurs even at the lowest plasma temperatures and particle impact energies, thus enhancing the transport of carbon to areas even remote from the main location of plasma-wall interactions. This leads finally to the codeposition of eroded and transported carbon with fuel atoms.

In a fusion reactor the codeposition of the radioactive fuel tritium has to be minimized because of safety 
reasons [e.g., $350 \mathrm{~g}$ for ITER (Ref. 1)]. This is the main reason to reduce the use of graphite in the current design of the next-step fusion device ITER. Instead of carbon, beryllium is foreseen for the first wall in the main chamber, and tungsten will be used for the baffles and for the dome. However, to withstand high power fluxes during off-normal events like disruptions, the divertor target plates will be made of carbon fiber composites.

Present experiments in existing devices aim to predict the wall erosion, material lifetime, and tritium retention in future machines. For that purpose modeling is indispensable. The TEXTOR tokamak with its limiter locks and a comprehensive set of diagnostics for plasma characterization and for studies of impurity release and transport is well suited to develop such models and to benchmark its relevant elements. This paper gives an overview of experiments carried out at TEXTOR that help to explain open, ITER-relevant questions in the field of erosion processes, transport of impurities, and their (re-)deposition. Since the establishment of the European Task Force for plasma-wall interaction in August 2002, the scientific programme at TEXTOR in the field of plasma-wall interaction is organized in cooperation with this task force.

\section{EROSION PROCESSES}

\section{II.A. Chemical Erosion}

\section{II.A.1. Chemical Erosion of Carbon-Based Materials due to Hydrogen Impact}

II.A.1.a. Laboratory Experiments. Chemical erosion of carbon-based materials under hydrogen and oxygen has been intensively studied in accompanying laboratory experiments. ${ }^{2}$ The experiments have been done using a conventional ion gun and a high-intensity atomic hydrogen beam $\left(10^{20} / \mathrm{m}^{2} \cdot \mathrm{s}\right)$ impinging simultaneously on heatable targets. The reaction products or sputtered species are detected in a two-stage differentially pumped lineof-sight mass spectrometer, allowing the direct tracing of particles and also radicals from the surface. Released species can be discriminated with a magnetically driven chopper, which allows one to determine their velocity distribution by time-of-flight analysis.

One of the most striking results is the discovery of the synergistic effect in chemical hydrocarbon formation: The simultaneous impact of hydrogen atoms with a small part of energetic ions (Ar ions in this case) leads to a drastically enhanced (more than ten times) formation of hydrocarbons by the atomic hydrogen. ${ }^{3}$ This effect has been reproduced by other groups under different combinations of ion and atom impact. Later, it was found that this enhancement also exists if the graphite surface was irradiated in advance by atomic hydrogen impact. ${ }^{4}$ Initially, the hydrocarbon formation on such preirradiated surfaces is enhanced compared with bare graphite until the damaged surface layer is chemically eroded, and then, the erosion decreases to values as observed for pure graphite. These observations have been fundamental to understand the synergistic effect: Energetic ion irradiation creates surface and lattice damage with which the atomic hydrogen reacts preferentially forming hydrocarbons. This enhanced erosion proceeds until the damaged layer is fully removed. Another important result is that under atomic impact the dominant released species is the methyl radical $\mathrm{CH}_{3}$ and not the saturated $\mathrm{CH}_{4}$ molecule. ${ }^{3}$ The formation of $\mathrm{CH}_{3}$ radicals has later been understood and explained in an atomistic model by Küppers et al. ${ }^{5}$

Further experiments proved that amorphous carbon layers produced by plasma chemical deposition (a-C:H films) showed also an enhanced erosion compared to graphite under atomic hydrogen bombardment, i.e., similar to synergistic bombardment and to preirradiated graphite. ${ }^{6}$ The yield reaches a maximum value of $\sim 10 \%$ (Fig. 1). A large family of hydrocarbons is formed with the majority of released species being higher $\mathrm{C}_{2}$-type hydrocarbons reaching about twice the yield of methane. Direct line-of-sight detection revealed again the emission of nonsaturated hydrocarbons, e.g., $\mathrm{C}_{2} \mathrm{H}_{5}$ (Ref. 6). Further insight into the hydrocarbon production mechanism was gained in experiments in which the graphite surface was saturated first with deuterium followed by hydrogen atom

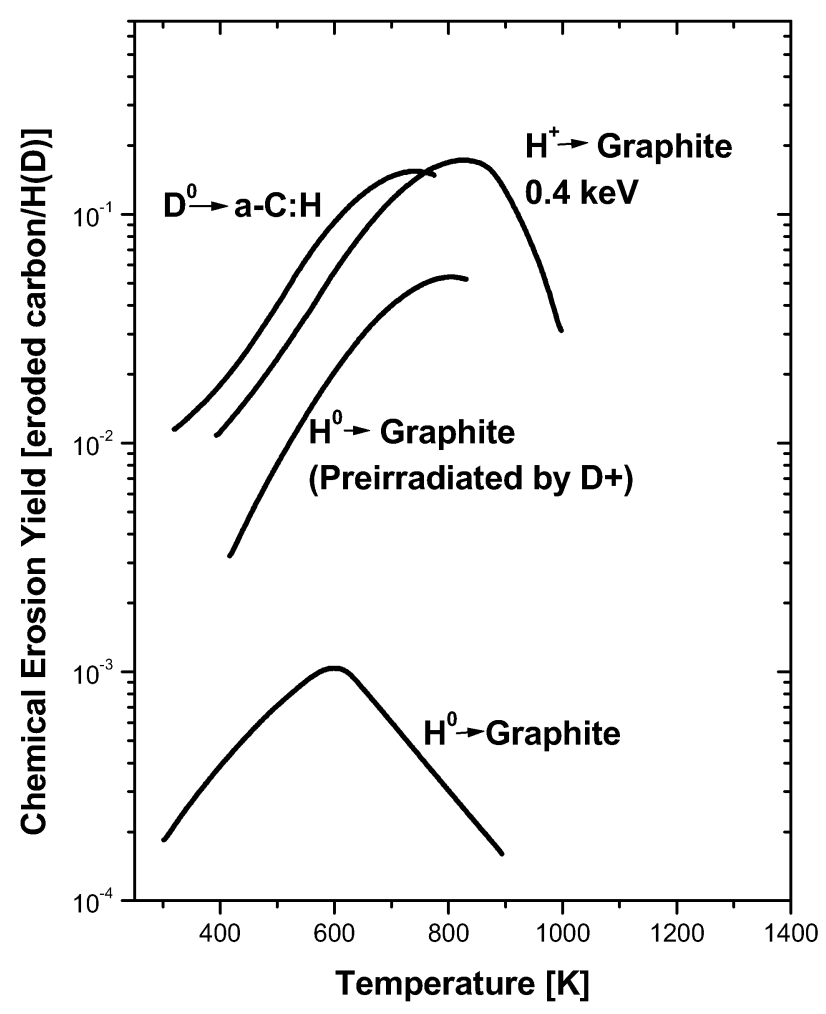

Fig. 1. Chemical erosion of various types of carbon materials dependent on surface temperature. 
impact, which produced hydrogenated hydrocarbons while the deuterium stored in the graphite surface was released in the form of HD molecules. ${ }^{7}$

Hydrocarbon formation depends in a complex manner on various parameters like surface temperature, ion impact energy, and flux density. For low impact energies characteristic of fusion conditions, hydrocarbons are also produced at temperatures $<500 \mathrm{~K}$ but vanish more or less at higher impact energies. Within the present model it is believed that the low-temperature branch is associated with a kinetic emission of hydrocarbon species formed in a surface layer by the hydrogen impact. Using timeof-flight mass spectrometry, the velocity distribution of emitted $\mathrm{CH}_{3}$ has been measured during the synergistic impact of $\mathrm{H}$ and $\mathrm{Ar}^{+}$at low target temperature. $\mathrm{CH}_{3}$ is emitted with an energy distribution lower than expected from a physical sputter process but is higher than a thermal Maxwellian distribution. ${ }^{8}$ Details of these processes are still not fully understood and await an explanation.

II.A.1.b. Experiments in TEXTOR. Methane formation is usually studied in the TEXTOR tokamak by observation of the band emission of the $\mathrm{CH}(\mathrm{D})$ radical at $431 \mathrm{~nm}$ or by spectroscopic detection of the $\mathrm{C}_{2}$ molecules as an indicator for higher hydrocarbon formation. ${ }^{9}$ Methane formation yields are evaluated from $\mathrm{CD}$ and $\mathrm{H}_{\gamma}$ light using (inverse) photon efficiencies of 100 and 1000 for $\mathrm{CD}$ and $\mathrm{H}_{\gamma}$, respectively, for TEXTOR standard plasma conditions $\left(T_{e}=30 \mathrm{eV}, n_{e}=2 \times 10^{18} / \mathrm{m}^{3}\right)$ (Ref. 10). In situ methane injection through a limiter (Fig. 2) is used to relatively calibrate the $\mathrm{CD}$ emission for other plasma conditions, in particular, for higher fluxes where $T_{e}$ and $n_{e}$ are increased by immersing the limiters more deeply inside the plasma (Ref. 10).

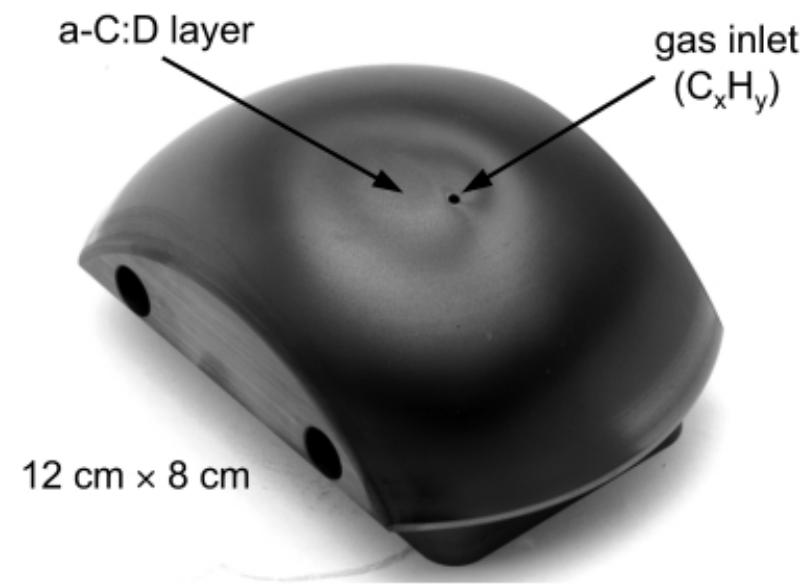

Fig. 2. Photograph of a graphite test limiter (mushroom shape), which is used in TEXTOR for hydrocarbon injection experiments.
In TEXTOR, most data have been obtained with the test limiters located at the last closed flux surface (LCFS). In deuterium-fueled discharges the methane yields range between 3 and $5 \%$. Similar to mass spectrometry the yields change little with varying plasma density and thereby with density of the hydrogen flux, ranging typically between $5 \times 10^{21} / \mathrm{m}^{2} \cdot \mathrm{s}$ up to several $10^{22} / \mathrm{m}^{2} \cdot \mathrm{s}$. Inserting the limiters more deeply into the plasma and using neutral beam injection heating increases the impinging flux densities up to several $10^{23} \mathrm{D} / \mathrm{m}^{2} \cdot \mathrm{s}$, whereas the methane yields decrease to values of $\sim 1 \%$. This is a clear indication for a flux-dependent decrease of the methane formation at higher fluxes, which is also seen in other experiments. ${ }^{11}$ One has to keep in mind that the plasma temperatures under those conditions rise to 80 to $100 \mathrm{eV}$, resulting in higher impact energies, which also influences the methane formation.

To evaluate the surface temperature dependence of chemical erosion, an externally heated limiter ${ }^{12}$ has been used in reproducible standard ohmic plasmas with the limiter tip at the LCFS, resulting in a medium deuterium particle flux at the location of the spectrometer view of $\sim 2 \times 10^{22} \mathrm{D} / \mathrm{m}^{2} \cdot \mathrm{s}$. The methane formation increases only moderately $(<50 \%)$ from room temperature and reaches a broad maximum extending from 450 to $\sim 1050 \mathrm{~K}$. Further increase of the surface temperature decreases the yield, reaching at $1400 \mathrm{~K}$ a value of $\sim 0.1$ of the yield at $600 \mathrm{~K}$, as shown in Fig. 3 (Ref. 10). Under TEXTOR conditions (energy and flux), the temperature profile is much broader as observed in beam experiments, and the decrease of the methane formation toward higher temperatures is shifted by $\sim 300 \mathrm{~K}$ to higher temperatures. Such a shift of the maximum of the chemical erosion peak is predicted by several models for

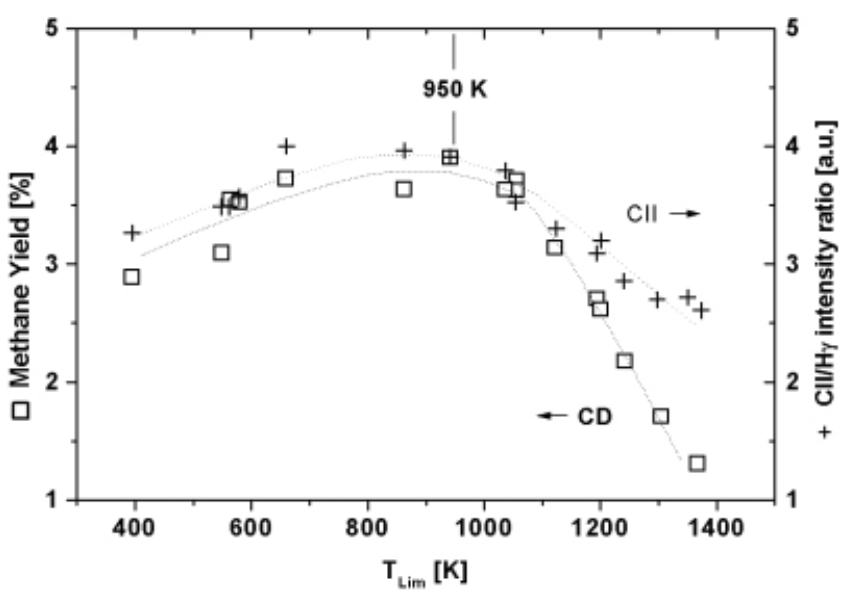

Fig. 3. Methane yield and CII/D-flux ratio for a graphite limiter as a function of limiter temperature for identical plasma discharges $\left[n_{e}(46 \mathrm{~cm})=3 \times 10^{13} \mathrm{~cm}^{-3}, T_{e}\right.$ $(46 \mathrm{~cm})=30 \mathrm{eV}]$. Flux density at the location of maximum flux was $\sim 2 \times 10^{22} \mathrm{D} / \mathrm{m}^{2} \cdot \mathrm{s}^{-1}$. 
hydrocarbon formation and can be understood in terms of a delayed decrease of the hydrogen concentration in the near-surface region at high-flux conditions. The data show that under the ITER divertor high-flux conditions, the chemical peak can extend to high temperatures. At lower temperatures $(<600 \mathrm{~K})$, the methane formation is still strong, and the underlying mechanism is believed to be a kinetic ejection of surface hydrocarbon complexes by collisional energy transfer. This is thought also to cause the observed isotope effect.

The overall carbon emission, as measured from CII line radiation $(426.7 \mathrm{~nm})$, decreases by about half when the $\mathrm{CD}$ light vanishes at high surface temperatures, showing that $40 \%$ of the carbon release originates from the hydrocarbon source whereas the remaining carbon must originate from physical sputtering by deuterium and selfsputtering by carbon ions. The physical sputtering yield of carbon for these conditions is $\sim 1.5$ to $2 \%$ from which a similar hydrocarbon emission is concluded as being in reasonable agreement with the methane emission derived directly from the $\mathrm{CD}$ light, taking into account some redeposition of hydrocarbons before they reach the CII state.

Methane release similar to that for pure graphite (EK98) is measured for copper and stainless steel limiters. This is due to the carbon flow in the edge and recycling on the surface. The yield thus reflects the carbon-todeuterium ratio in the scrape-off layer (SOL). In contrast to that, the hydrocarbon formation yields at Mo and $\mathrm{W}$ limiters are significantly lower.

No systematic study of higher hydrocarbon formation has been made in TEXTOR, but a few measurements of a $\mathrm{C}_{2}$ molecular band emission at $516.5 \mathrm{~nm}$ were performed. The $\mathrm{C}_{2}$ band emission is detectable at high plasma densities. $\mathrm{CH}_{4}$ and $\mathrm{C}_{2} \mathrm{H}_{4}$ puffing shows that the ratio of methane to higher hydrocarbon emission is about onethird under typical TEXTOR conditions. ${ }^{10}$ Hydrocarbon formation has also been measured by mass spectrometry of the neutral gas near the wall and by using a special sniffer probe where higher fluxes and geometrically defined conditions are achieved. ${ }^{13}$ This system acts as a small pump limiter unit positioned in the SOL typically $>1 \mathrm{~cm}$ behind the LCFS in order to avoid excess heat fluxes. A plasma column impinges through an aperture $(4 \times 7 \mathrm{~mm})$ onto a graphite strip, which can be heated. Formed hydrocarbons and recycled hydrogen build up a neutral gas pressure at the end of the tube, which is sampled by a quadrupole mass spectrometer. These species have to travel long distances before they are detected. It is assumed that radicals recombine at the chamber walls into saturated molecules and that their sticking to the walls is negligible. Under typical TEXTOR conditions the ion flow consists of a mixture of deuterium and hydrogen, leading to formation of mixed hydrogen isotopes with an isotopic fraction of a reaction of fourth order. Measured ion fluxes in the sniffer probe are typically 20 to $50 \%$ larger than the hydrogen fluxes evaluated from the pressure rise at the end of the tube. This is in reasonable agreement if the charge contribution of impurity ions impinging on the target is taken into account.

The methane yields evaluated from the pressure rises are between $\sim 0.7$ and $1.2 \%$ at target temperatures $<500 \mathrm{~K}$ and do not depend much on plasma parameters. There is only a weak tendency of decreasing yields with increasing flux density within this flux range. Upon increasing the target temperature, the methane yields increase by a factor between 1.5 and 2 , reaching values up to $\sim 2 \%$, which is somewhat lower as inferred in TEXTOR by means of spectroscopy. Under carbon-dominated wall conditions in TEXTOR (old boronization or siliconization), the sum of the $\mathrm{C}_{2}$ hydrocarbons reaches similar yields to methane and thus dominates the carbon erosion. Siliconization and boronization reduce the $\mathrm{C}_{2}$-hydrocarbon formation but do not reduce the methane production much.

II.A.1.c. Flux Dependence of Chemical Erosion: Current Status. The TEXTOR data on graphite chemical erosion were also used in data collection of experiments from various laboratory, linear plasma simulators, and tokamak experiments to obtain a more consistent picture of chemical erosion. ${ }^{14}$ The data clearly show flux dependence with a reduction of the erosion yield at $10^{24} / \mathrm{m}^{2} \cdot \mathrm{s}$ from $3 \times 10^{-2}$ to $\leq 5 \times 10^{-3}$. First implications for ITER are discussed in detail ${ }^{14}$ using the ERO code for modeling the carbon transport and taking into account the dependence of chemical erosion on incoming flux, surface temperature, and impact energy of hydrogen. Compared to a fixed yield of $1 \%$, the erosion is reduced by a factor of 30. However, there is still a need for improved modeling taking into account the effect of beryllium codeposition and ELMs.

\section{II.A.2. Chemical Erosion due to Oxygen Impact}

In molecular beam experiments, $\mathrm{CO}$ formation from graphite due to $\mathrm{O}_{2}$ exposure at equivalent pressures of $\sim 10^{-3} \mathrm{~Pa}$ has been observed above $1000 \mathrm{~K}$. The observed maximum yield at $1300 \mathrm{~K}$ reaches values of $\sim 2 \times$ $10^{-3}$ released $\mathrm{CO} / \mathrm{O}_{2}$ (Ref. 15). The $\mathrm{CO}$ formation under simultaneous bombardment of graphite by $\mathrm{Ar}^{+} / \mathrm{O}_{2}$ is shown in Ref. 2 . However, at the maximum, $\sim 1300 \mathrm{~K}$, the $\mathrm{CO} / \mathrm{O}_{2}$ yield is only doubled in comparison with the case of $\mathrm{O}_{2}$ exposure alone, probably due to the simultaneous annealing of defects at this temperature. ${ }^{15}$

When energetic oxygen ions impinge on graphite, the implanted oxygen is trapped in a transient stage and then reemitted as $\mathrm{CO}$ or $\mathrm{CO}_{2}$. No reemission of $\mathrm{O}$ and $\mathrm{O}_{2}$ has been found. When saturation is reached, all of the newly implanted oxygen ions react to form $\mathrm{CO}$ or $\mathrm{CO}_{2}$, as shown in Fig. 4. The $\mathrm{CO}$ formation yield and the total chemical erosion yield show no pronounced temperature dependence. The yield for the minor component $\mathrm{CO}_{2}$ has a maximum at $\sim 600 \mathrm{~K}$ and vanishes for temperatures 


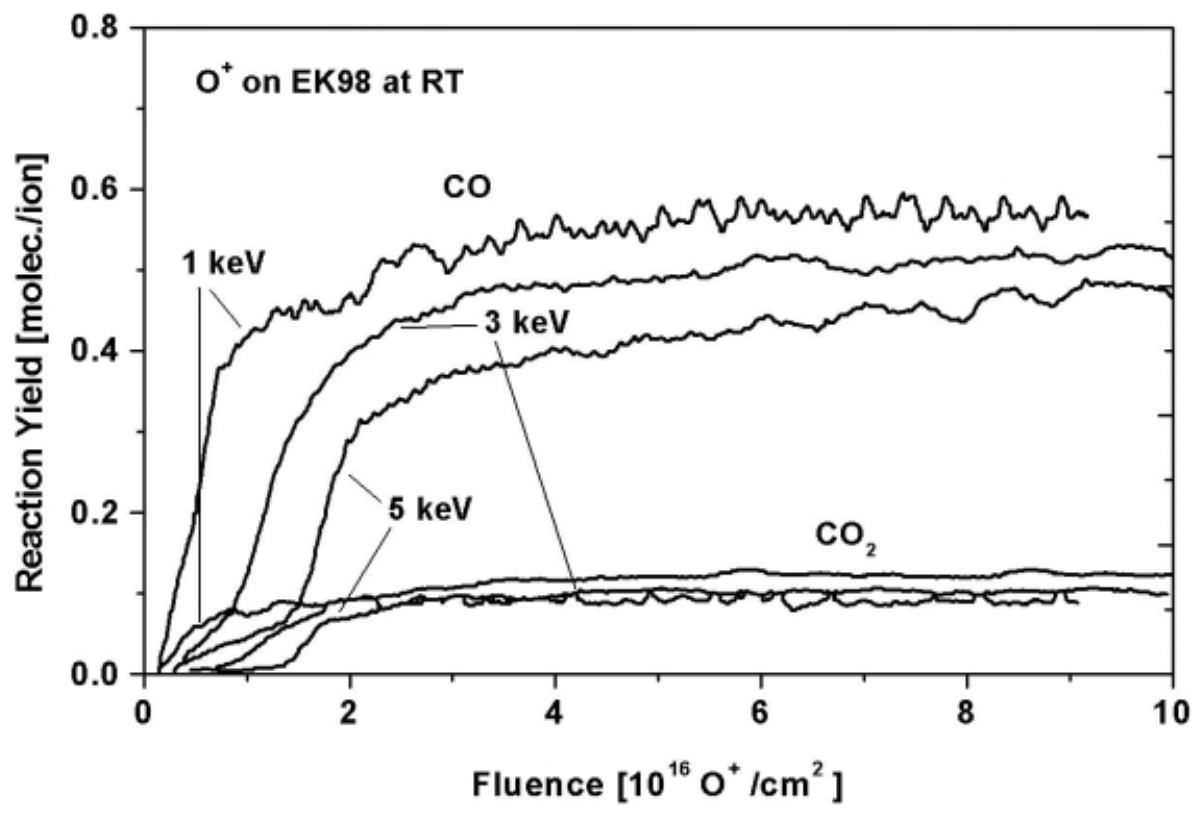

Fig. 4. Release of $\mathrm{CO}$ and $\mathrm{CO}_{2}$ from EK98 irradiated with 1,3 , and $5 \mathrm{keV}$ of $\mathrm{O}^{+}$at room temperature. Incident ion flux densities were $5 \times 10^{13}, 2.2 \times 10^{14}$, and $2.6 \times 10^{14} \mathrm{O}^{+} / \mathrm{cm}^{2} \cdot \mathrm{s}$, respectively.

above $1400 \mathrm{~K}$. The total $\mathrm{C}$ erosion yield, i.e., the sum of chemical erosion and physical sputtering, is nearly temperature independent and has a value between 0.7 and 1.0 for temperatures $<1000 \mathrm{~K}$ and incident $\mathrm{O}^{+}$energies $>500 \mathrm{eV}$.

During thermal desorption of implanted oxygen from graphite, the retained oxygen is also released completely in the form of $\mathrm{CO}$ and $\mathrm{CO}_{2}$. The $\mathrm{CO}_{2}$ desorbs at $\sim 700 \mathrm{~K}$ and $\mathrm{CO}$ at $\sim 1000 \mathrm{~K}$, which is very similar to the thermal desorption behavior of graphite with chemisorbed $\mathrm{O}_{2}$. The desorption spectra are relatively broad, indicating that the oxygen is bonded with more than one energy. ${ }^{16}$

The velocity distribution of $\mathrm{CO}$ emitted from graphite and $\mathrm{B}_{4} \mathrm{C}$ under energetic oxygen bombardment has been measured using time-of-flight techniques. ${ }^{17}$ It is found that the spectrum can be fitted reasonably well with a Thompson distribution corresponding to a binding energy of 0.3 to $0.5 \mathrm{eV}$. Such small energies are not consistent with a normal sputtering mechanism (a compound with $0.3-\mathrm{eV}$ binding should dissolve at room temperature), but a final model to explain these energies is still missing.

The erosion of carbon in fusion devices by residual oxygen impurities via the formation of $\mathrm{CO}$ molecules has been observed in TEXTOR by optical spectroscopy and residual gas analysis in the sniffer probe and near the walls. In general the oxygen impurity level is coupled by these chemical processes with the carbon impurity level. A clear correlation of the oxygen and carbon impurity level has been stated in various devices.

Chemical erosion of molybdenum and tungsten via the production of volatile oxides at higher temperatures is observed and reported in literature. An analysis of this has been tried in TEXTOR high-Z test limiter experiments by heating the limiters to very high temperatures. When the high-Z limiters approach high temperatures $(>1700 \mathrm{~K})$, oxygen is released and leads to a locally enhanced oxygen flux. This also increases the brilliance of WI light but, if normalized to the oxygen flux, is consistent with the assumption of tungsten physical sputtering. ${ }^{18}$

\section{II.B. Radiation-Enhanced Sublimation}

A surprising discovery in the investigation of the erosion of carbon by energetic particle impact was the anomalously enhanced erosion yield above $1300 \mathrm{~K}$ (Refs. 19 and 20) described by an exponential increase of the yield with the reciprocal temperature, $Y=Y_{0} \times$ $\exp \left(-E_{\text {res }} / k T\right)$, where $E_{\text {res }}$ denotes the activation energy of the radiation-enhanced sublimation (RES) yield, which is in the range of 0.6 to $0.9 \mathrm{eV}$, and $Y_{0}$ is a prefactor. RES of carbon materials consists of the isotropic emission of single carbon atoms in contrast to normal thermal sublimation, which is characterized by the emission of $\mathrm{C}_{2}$ and $\mathrm{C}_{3}$ clusters. ${ }^{19}$ The energy distribution of RES emitted carbon atoms measured using time-of-flight detection shows thermal velocities in accordance with the carbon surface temperature, as shown in Fig. 5. The yield scales approximately with the nuclear energy deposited by the bombarding particle in the near-surface layer by collision processes, assuming a transferred energy threshold of $\sim 20 \mathrm{eV}$, and is thus characterized by a steep decrease with decreasing energy at low impact energies. The main 


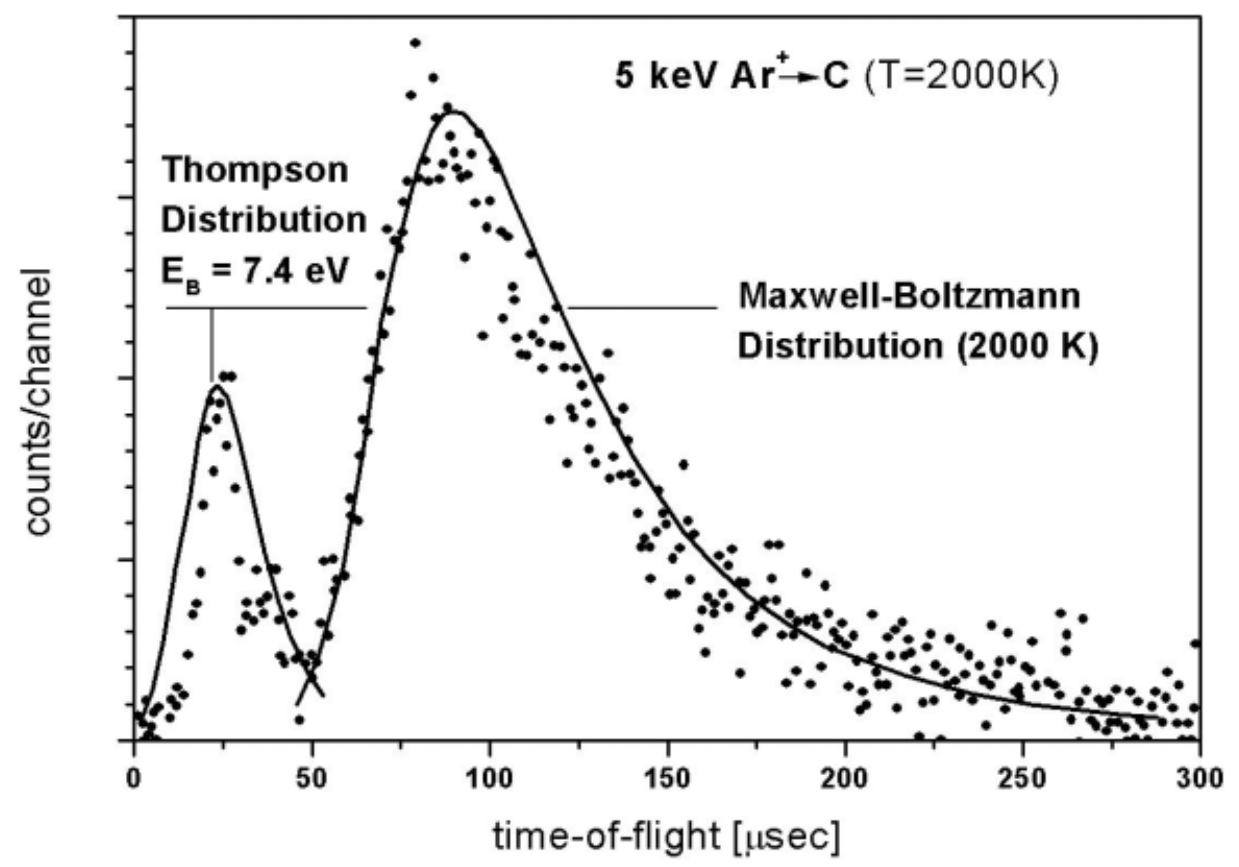

Fig. 5. Time-of-flight spectrum of physically sputtered and RES emitted carbon during bombardment of graphite with 5 keV Ar at $T=2200 \mathrm{~K}$.

features of this effect, such as yields, velocity distribution, and temperature dependence, can be reasonably well explained with a model in which RES is caused by radiation-produced interstitials that diffuse to the surface in competition with annihilation at internal defects. ${ }^{21}$ These interstitials are loosely bound to the surface and evaporate thermally. However, some data such as the time transient behavior and the independence of the yields of flux density in laboratory experiments are in disagreement with the interstitial model. RES emission from carbon test limiters has been intensively studied in TEXTOR by optical emission spectroscopy. Limiters have been exposed to heat loads of typically 10 to $20 \mathrm{MW} / \mathrm{m}^{2}$ for typically 1 to $2 \mathrm{~s}$ with corresponding deuterium flux densities of $10^{23} \mathrm{D} / \mathrm{m}^{2} \cdot \mathrm{s}$, resulting in peak surface temperatures of up to $2400^{\circ} \mathrm{C}$. Locally resolved spectroscopy of $\mathrm{CI}$ and CII emission lines show that the increase of the carbon emission is $<15 \%$ when the peak surface temperature reaches $\sim 1900^{\circ} \mathrm{C}$, and spatially resolved profiles show that the slight increase of carbon light is restricted to a near-surface region. ${ }^{22}$

It was speculated that the fast-rising transient temperatures may delay the onset of RES. Therefore, experiments were carried out with an externally preheated graphite limiter to $1400 \mathrm{~K}$ followed by slow heating by an ohmic target plasma to $\sim 1800 \mathrm{~K}$ at the end of the discharge. ${ }^{21}$ Again, no significant increase of the ratio of $\mathrm{CII} / \mathrm{H}_{\gamma}$ emission was observed when the limiter surface temperature increased continuously. This clearly demonstrates that the carbon release under the TEXTOR impact conditions is not significantly enhanced, which, however, is not fully understood in terms of the RES model and understanding.

\section{IMPURITY TRANSPORT, DEPOSITION, AND ITS MODELING}

\section{III.A. Erosion and Transport of High-Z Elements}

High-Z metals, e.g., tungsten and molybdenum, with high melting point and high threshold energy for sputtering by hydrogen isotopes have been extensively examined at TEXTOR since 1992 in close cooperation with the Japanese partners. ${ }^{23,24}$ Figure 6 shows a mushroomshaped tungsten brush limiter exposed for $\sim 600 \mathrm{~s}$ of plasma operation, i.e., some 100 pulses. The power deposited on such limiters reaches typically up to $7 \%$ of the total plasma power during the exposure inside the LCFS defined by the position of the main toroidal limiter, Advanced Limiter Test (ALT) II (ALT-II).

Tungsten sputtering yields normalized to hydrogen impact range between 3 (low densities) and $\sim 0.5 \%$ (highest densities). However, tungsten is nearly exclusively sputtered by carbon and oxygen impurity impact. Estimated sputter data using measured deuterium, carbon, and oxygen fluxes show good agreement with the effective tungsten release rates. ${ }^{25}$ This is in accordance with the measured erosion rate of $\sim 4 \mathrm{~nm} / \mathrm{s}$ for tungsten that cannot be explained by erosion due to the impinging 


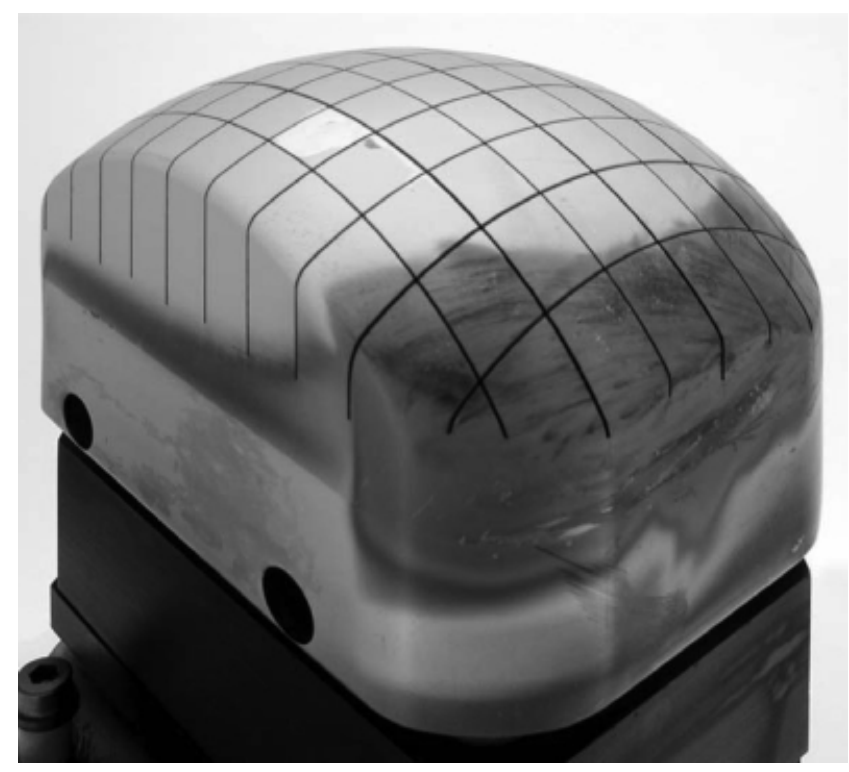

Fig. 6. Photograph of a mushroom tungsten brushlike limiter.

deuterium ions. The appearance of prompt redeposition (redeposition during the first gyration) of high-Z atoms reduces the net erosion and is therefore promising for the utilization of high- $\mathrm{Z}$ materials. ${ }^{26,27}$ This effect is calculated from measured plasma parameters and indicated from collector probe measurements ${ }^{28}$ showing that the net eroded amount of tungsten is about seven times smaller than that of molybdenum under the same conditions, which is in good agreement with model estimations taking into account sputtering, ionization, gyration, and prompt redeposition.

Special test limiter experiments have been done in TEXTOR to investigate the local transport of high-Z tungsten and of medium- $Z$ silicon for comparison..$^{29} \mathrm{An}$ edge was introduced artificially on the $\mathrm{W}$ - and Si-coated limiter, creating a local shadow region with respect to the field lines. The Si and $\mathrm{W}$ films had totally been eroded and partly transported to the shadowed region with amounts between 3 and $8 \%$ for the eroded tungsten, but only $0.4 \%$ for $\mathrm{Si}$. While for tungsten repetitive prompt redeposition $(\approx 50 \%)$ within the first Larmor orbit seems to play a big role, the silicon transport is dominated $(\approx 70 \%)$ by longer-range transport of ions and their redeposition. The larger ionization length for Si explains the lower redeposition efficiency compared to W.

In general, the core plasma transport determines the behavior of the main plasma. In ohmic discharges the radiated power increment due to the high- $Z$ impurities penetrating into the main plasma increases with plasma density although the impurity release is decreased. A plasma thermal instability is reached at a critical density. The critical density has been explained in terms of neoclassical transport of the high-Z impurities. ${ }^{30}$ The neoclassical flux is balanced by the flux due to anomalous diffusion. A central $T_{e}(r)$ flattening due to high-Z radiation causes the neoclassical inward flux of high- $Z$ species to dominate since the temperature screening disappears. This finally leads to instability. In auxiliary heated discharges the anomalous transport increases and dominates over the neoclassical transport, thus preventing high- $Z$ accumulation. The threshold heating power level can be understood in terms of neoclassical and anomalous diffusivity and heat conductivity. ${ }^{30}$ Neon puffing for edge cooling enhances the high- $Z$ accumulation.

Impurity deposition measurements on the ALT-I limiter heads in TEXTOR reveal significant metal accumulations on the ion and electron side of the limiter. ${ }^{31}$ From the composition it is concluded that the source of this deposition is mainly from erosion of the main limiter, which was from stainless steel at this time. On the ALT-I limiter front faces, a maximum metal concentration occurs near the tangency point. Modeling with the Redep code $^{32}$ can reproduce the deposition patterns and explain the impurity accumulation at the tangency point by a successive transport to these regions via erosion and redeposition and finally a decreased erosion at the tangency point caused by background flux impinging nearly parallel to the surface.

A review of experiments with tungsten and high- $Z$ materials as PFCs in magnetic fusion devices is given in Ref. 23. Here, results from TEXTOR but also from other machines like ASDEX, Alcator C-Mod, DIII-D, and FTU are summarized and compared with each other.

\section{III.B. Low- and High-Z Twin Limiter Experiments}

Twin limiters consisting of two parts of the same geometry have been used in TEXTOR. Normally, one part is made of high-Z, and the second is made of graphite, but $\mathrm{W}$ and Ta here also have been used. ${ }^{33}$ The experiments are focused on direct comparison of material behavior under the same plasma conditions. Similar exposure conditions of the two limiter halves are ensured by rotating $(180 \mathrm{deg})$ the limiter holder between two very similar discharges. The program has been concentrated on comparative studies of thermal response, ${ }^{34}$ particle recycling, ${ }^{33}$ fuel inventory, ${ }^{35}$ and material mixing. ${ }^{36}$ Fuel inventory in tungsten was estimated to values $<1 \times 10^{15}$ $\mathrm{D}$ atoms $/ \mathrm{cm}^{2}$ retained in a thin surface layer only. ${ }^{37}$ Eroded tungsten locally migrates to a significant extent to the adjacent plasma-facing surfaces, ${ }^{38}$ which leads to an accumulation on the graphite part of the limiter close to the tangency point including the gap area between the two parts of the twin limiter. The major transport mechanism of tungsten is thought to be by stepwise prompt redeposition and erosion. On the hottest parts of the limiter, the formation of mixed W-C-B compounds is observed. On the tungsten part of the twin limiter, a thick blackish codeposit is found only on the far end of the limiter (this can be explained in terms of a flux balance of incoming deposited carbon from the background plasma, 
reflection, and reerosion $\left.{ }^{25,39}\right)$ and on the topmost part (3 to $4 \mathrm{~mm}$ wide) of the gap. The majority of the plasmafacing surface and the rest of the gap area remain shiny. Metal migration and deposition on surfaces in the gaps between the limiter have been observed and could be explained only in terms of erosion caused by local electric discharges.

\section{III.C. Local Nonuniform Carbon-Boron Deposition}

A major conclusion drawn from observations of in situ erosion of a B-C layer is that erosion of the boron can occur simultaneously with carbon deposition from the background plasma up to a thickness much higher than the implantation depth. ${ }^{40}$ The reason is the nonuniformity of the carbon deposition, which does not perfectly protect the boron surface and allows simultaneously nonuniform $\mathrm{B}$ erosion. With average rates of about +0.8 $\mathrm{nm} / \mathrm{s}$ for $\mathrm{C}$ and $-0.5 \mathrm{~nm} / \mathrm{s}$ for $\mathrm{B}$, the carbon thickness can grow to $300 \mathrm{~nm}$ while the neighbored boron loses $100 \mathrm{~nm}$. Characteristic of the "islands" is an irregular shape and sizes of 10 to $30 \mu \mathrm{m}$, which is on the order of the microstructure of the carbon flakes, as shown in Fig. 7. Because of the increased lifetime of the film, boron remains active longer as getter for oxygen impurities in the machine. This benefit is with the cost of a growing tritium reservoir due to the carbon deposit, both relevant

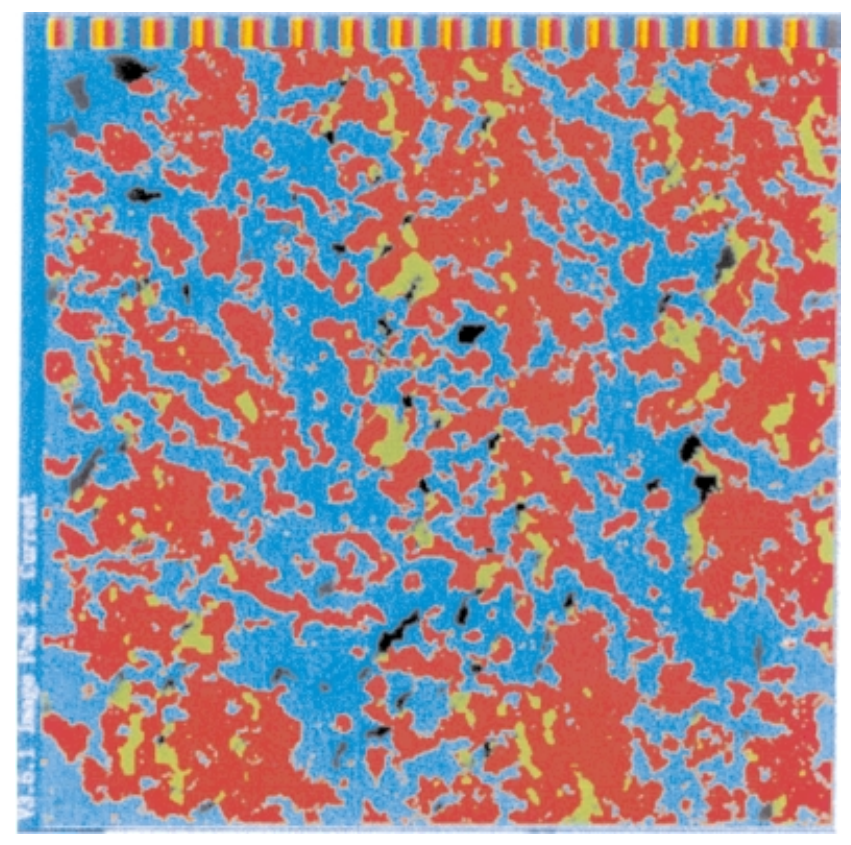

Fig. 7. Distribution of carbon and boron in an area of $65 \times$ $65 \mu \mathrm{m}$ as found by wavelength dispersive X-ray mapping in deposition zone; red: carbon only, no boron; blue: carbon as well as boron; yellow: boron only, no carbon; black: no signal. for ITER. Despite boron erosion the deuterium content is found to be increased by a factor $>2$ in the carbon deposition zone compared to the virgin a-B:D.

\section{LOCAL TRANSPORT STUDIES USING ${ }^{13} \mathrm{CH}_{4}$ AND $\mathrm{SiH}_{4}$ INJECTION THROUGH TEST LIMITERS}

To study the local transport and redeposition behavior of hydrocarbons (Refs. 13 and 29), $\mathrm{CH}_{4}$ has been injected through a hole in a graphite limiter. The use of ${ }^{13} \mathrm{CH}_{4}$ is beneficial because ${ }^{13} \mathrm{C}$ behaves like a "tracer" impurity in a surrounding of mainly ${ }^{12} \mathrm{C}$, and carbon deposition from the puffing and the deposition from the background ${ }^{12} \mathrm{C}$ flux can be discriminated. $\mathrm{CH}$ and $\mathrm{CII}$ radical emission adjacent the hole is observed by spectroscopy, while the incremental growth of the deposit is measured in situ by colorimetry. ${ }^{41}$ SIMS depth profiling yielded the fractions of ${ }^{13} \mathrm{C}$ and of ${ }^{12} \mathrm{C}$ out of the background, giving ratios up to ${ }^{13} \mathrm{C} / \mathrm{C} \approx 0.42$ at the limiter surface whereas the local deposition efficiency of ${ }^{13} \mathrm{C}$ $<0.5 \%$.

More than $99 \%$ of the introduced ${ }^{13} \mathrm{C}$ is lost locally and penetrates into the edge plasma and recycles at other locations inside the machine from which it feeds the carbon flux in the SOL with a corresponding isotopic ratio. The redeposition should show a carbon isotopic ratio independent of the radial distance, which is indeed observed on a target mounted perpendicularly to the toroidal direction at the side surface of the test limiter, where a constant ratio ${ }^{13} \mathrm{C} / \mathrm{C} \approx 0.27$ is measured, despite increasing thickness of the deposit up to $1 \mu \mathrm{m}$. In contrast, on the limiter surface itself, this ratio is not constant and increases up to 0.42 toward the location of the ${ }^{13} \mathrm{CH}_{4}$ injection.

Simulations with the ERO-TEXTOR code assuming a sticking of 50\% for charged hydrocarbon radicals ${ }^{13} \mathrm{CH}_{\mathrm{y}}$ and zero sticking for neutral species lead to a ${ }^{13} \mathrm{C}$ deposition efficiency of $\sim 40 \%$, which is much larger than the measured one. ${ }^{42}$ The simulations made use of the EhrhardtLanger ${ }^{43}$ database for the rate coefficients of ionization and dissociation for hydrocarbons of the methane family. In addition, the simulated ${ }^{13} \mathrm{C}$ deposition pattern on the limiter surface shows in the experiment a maximum deposition located $\sim 2$ to $3 \mathrm{~cm}$ away from the injection hole, whereas the simulation gives a maximum exactly at the position of the injection. However, the general trend of a tilted deposition pattern relative to the magnetic field lines is reproduced by the modeling and can be explained by an $\mathrm{E} \times \mathrm{B}$ drift where the radial electric field $\mathrm{E}$ is caused by the gradient of the electron temperature above the limiter surface.

The two-dimensional distribution of the emitted light $(\mathrm{CH}$ and $\mathrm{CII})$ above the test limiter can be well reproduced by the simulations. Variations of the plasma parameters in the simulation (e.g., decreasing the local electron temperature due to cooling caused by the injection 
and simultaneous increase of the density) have little effect on the simulated pattern and deposition efficiency. As a key parameter, the direct reerosion of all redeposited hydrocarbon radicals has been identified. This extreme case is modeled by assuming zero sticking for all hydrocarbons, corresponding to very high reerosion of the freshly deposited hydrocarbon layer. The simulated deposition efficiency is decreased to $2.5 \%$, and much better agreement of the simulated and observed ${ }^{13} \mathrm{C}$ deposition pattern is achieved. This assumption is backed by the observation that a-C:H films formed in glow discharges at low self-bias (soft films) show drastically increased erosion by hydrogen. ${ }^{44}$

Recently in the simulations new rate coefficients for the methane family from Janev have been used ${ }^{45,46} \mathrm{How}-$ ever, this increases the deposition efficiency to $\sim 12 \%$ compared to the former $2.5 \%$. To model the low deposition efficiency of $\sim 0.5 \%$, in addition to zero sticking of hydrocarbons (high "self-reerosion"), an enhanced chemical erosion of redeposited carbon atoms and ions caused by the background is assumed ( $8 \%$ compared to $2 \%$ for the graphite substrate material). Figure 8 summarizes a comparison of measured and simulated deposition patterns for the various assumptions. The redeposition of carbon and successive reerosion with a high probability can result in long-range transport, which finally ends up as accumulation on plasma-shadowed regions.

Recently, the transport of injected ${ }^{13} \mathrm{C}$ marked methane molecules was also investigated in the divertor machines Joint European Torus (JET), ASDEX Upgrade, and DIII-D. The evaluation of the JET and DIII-D experiments shows that ${ }^{13} \mathrm{C}$, which is injected at the top of the machine, is mainly deposited in the inner divertor. ${ }^{47-49}$ This proves the existence of asymmetric SOL flows into the direction of the inner divertor. First analysis of ${ }^{13} \mathrm{CH}_{4}$ injection experiments in the outer divertor ASDEX Up-

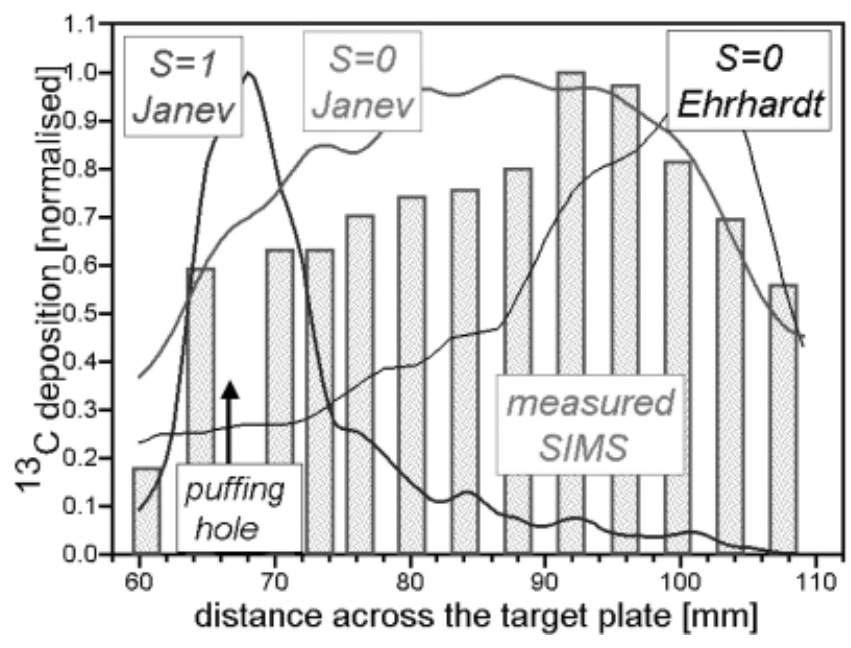

Fig. 8. Modeled and measured ${ }^{13} \mathrm{C}$ deposition profiles along the surface of a roof limiter after local ${ }^{13} \mathrm{CH}_{4}$ injection. grade reveals a high deposition (almost 100\%) around the location of injection. ${ }^{50}$ First ERO modeling qualitatively agrees with this result. Even if zero sticking for hydrocarbons is assumed, the molecules are effectively trapped inside the divertor, finally leading to a deposition of reeroded particles in the divertor itself.

At TEXTOR silane $\mathrm{SiD}_{4}$ has also been injected through spherically shaped test limiters ${ }^{51}$ resulting in a Si deposition efficiency of $\sim 5 \%$. Again, the layer contains large amounts of carbon from the background $\mathrm{C}$ flux. The aim was to explore the efficiency of in situ repair of wall protective films and the local transport of carbon and silicon. LIF measurements of SiI were also performed upon injection of $\mathrm{SiD}_{4}$, showing an atomic temperature of $\sim 0.6 \mathrm{eV}$ and radial density profiles displaced into the plasma, indicating molecular dissociation as a local source of atoms. ${ }^{52}$

\section{TESTS OF PLASMA-FACING CANDIDATE MATERIALS IN TEXTOR}

Various carbon-based composites doped with boron, silicon, or titanium have been tested in TEXTOR, mainly associated with the hope to reduce chemical erosion, as observed under laboratory conditions in ion beam experiments. Tested materials include Si doped carbon fiber (NS31 produced by Snecma, ${ }^{53}$ and SiC30), titanium doped graphite (RGTi), various B-doped graphites (carbon Lorraine, Toyo tanso), and $\mathrm{B}_{4} \mathrm{C}$ coating $(170 \mu \mathrm{m})$ on copper. ${ }^{54}$ The main mechanism to release silicon from a SiC30 material was physical sputtering. As demonstrated in situ by laser-induced fluorescence, ${ }^{52}$ the velocity profile corresponds to the well-known Thompson distribution (surface energy $\sim 4.8 \mathrm{eV}$; penetration depth $8 \mathrm{~mm}$ ), whereas the chemical release of silicon in the form of $\mathrm{SiD}_{4}$ gives a thermal distribution $\left(T_{S i I}<1 \mathrm{eV}\right)$. The contribution of the chemical distribution is $<6 \%$ for the conditions of the measurement. ${ }^{55}$

Poloidal limiter tiles have been replaced by externally cooled copper blocks coated with a $170-\mu \mathrm{m}$ VPS $\mathrm{B}_{4} \mathrm{C}$ layer. Similar limiters have been inserted through a limiter lock, extensively diagnosed in situ and ex situ. ${ }^{56}$ During the thermal load caused by the plasma, the surface temperature rose and decayed extremely fast, which is explained by the different thermal conductivities and heat capacities of the coating and the substrate. No severe cracking or exfoliation of the coating below heat loads of $8 \mathrm{MW} / \mathrm{m}^{2}$ happened. Thermomechanical stresses could partially be compensated by plastic deformation of the copper. Because of the insulating behavior of the $\mathrm{B}_{4} \mathrm{C}$ layer, distinct craters developed on both limiter types, which reached down to the copper surface and are assumed to be caused by electrical arcs. A periodic oscillation of the evolution of the surface temperature has been observed under certain conditions, which is clearly 
correlated to the use of the coated test limiter. Particle release properties turned out to be very similar to those from low-Z surfaces in a carbon surrounding. The hydrogen inventory, however, may be significantly higher in destroyed areas. No significant impact on the plasma was observed.

\section{LONG-RANGE CARBON TRANSPORT AND FUEL BALANCE IN TEXTOR}

\section{VI.A. Carbon Balance}

The main area of plasma-wall interaction in TEXTOR is the toroidal belt limiter with a surface area of $3.4 \mathrm{~m}^{2}$ covering $\sim 10 \%$ of the total inner surface of the torus. The noncircular poloidal curvature of the tiles of the central part of the blades limits the plasma at $r=$ $46 \mathrm{~cm}$, while the outer regions rise into the SOL by $\sim 2 \mathrm{~cm}$. This leads to a poloidal asymmetry of the incident field lines and to corresponding carbon erosion and deposition patterns.

One representative tile of the toroidal limiter has been instrumented to measure surface profiles against reference points by means of a laser profiler before and after plasma exposure. ${ }^{29}$ In the central part of the graphite tile, the erosion is found to be $\approx 4.8 \mu \mathrm{m} / \mathrm{h}$. In the area more distant from the plasma, the erosion is found to be larger (up to $13.4 \mu \mathrm{m} / \mathrm{h}$ ), and toward the end of the tile, the erosion rate decreases again. On the average, $5.4 \mu \mathrm{m} / \mathrm{h}$ is lost at two-thirds of the surface area, which corresponds to a total carbon source of $\approx 22 \mathrm{~g} / \mathrm{h}$. The part of the surface closest to the LCFS cannot be reached by ions because of the almost grazing incidence of the field lines, and therefore it turns into a net deposition zone. A large part of the eroded carbon is directly deposited on the tile's surface itself. Related to the total exposure time, this corresponds to $\sim 10 \mathrm{~g} / \mathrm{h}$. The deposited layer is stratified equidistantly according to the three boronizations applied in equal time intervals. It separates the strata by a thin boron marker. The net deposition rate remains nearly constant over an operation period of several months.

Obviously, the eroded carbon is transported over short distances over the surface, as suggested by the deposition of carbon in holes drilled along the surface where the presence of a deuterium-containing carbon film is indicated here by the codeposited $\mathrm{C}$ and D. Hydrocarbon radicals eroded in the direct surroundings can obviously be redeposited on the bottom. This observation highlights the high sensitivity of net effects due to surface imperfections in areas of shallow incidence. Grooves a few tenths of a millimeter can switch easily from net erosion into net deposition even on plasma-wetted components. Erosion in the shadowed grooves is only due to neutral hydrogen. ${ }^{29}$

Carbon not redeposited locally enters the edge plasma from where it may enter the plasma core or diffuse di- rectly in the SOL where it is deposited as $\mathrm{C}^{n+}$ ions on protruding obstacles as, e.g., the poloidal limiters and the protection tiles for the ion cyclotron resonance heating antennas. ${ }^{57}$ Their effective area is small $\left(\approx 0.2 \mathrm{~m}^{2}\right)$, but the average net deposition rate is as high as $\sim 4$ to $5 \mathrm{~nm} / \mathrm{s}$ because of the perpendicular intersection of the field lines. This ends up being a carbon deposition rate of $\sim 6 \mathrm{~g} / \mathrm{h}$. Other surfaces do not take part much in the carbon interchange, as the contribution of the torus shaped and boronized liner is about zero, ${ }^{58}$ serving only as a small but permanent source of boron instead. Little information is available at present for the graphite bumper limiter $\left(\approx 6 \mathrm{~m}^{2}\right)$ on the high-field side. Scanning ion mass spectrometry depth profiles taken at several locations on one tile suggest a slight net deposition of not more than $0.5 \mu \mathrm{m}$ over about two-thirds of the total area, which results in a rate of 1 to $2 \mathrm{~g} / \mathrm{h}$ of carbon.

The rest of the carbon $(\approx 5 \mathrm{~g} / \mathrm{h})$ not found inside the torus should have left via the pump ducts, where a significant net deposition is found on the neutralizer plates at the entrance of the pump ducts, with layers growing to thick crusts in the millimeter range within $5 \mathrm{yr}$ of operation. ${ }^{59}$ The material has been scratched off, resulting in $23.1 \mathrm{~g}$, corresponding to a total plasma exposure time of $\approx 24 \mathrm{~h}$, giving another $1 \mathrm{~g} / \mathrm{h}$. Obviously, reerosion takes place at the neutralizer plates, but only little deposition was found on the inner areas of the cold pump ducts (see Sec. VI.C). Most of the carbon released at the neutralizer plates seems to be neutral methane molecules and is pumped out. Extrapolation of sniffer probe data taken with geometry similar to the ALT pump limiter situation suggests a rate of 1 to $2 \mathrm{~g} / \mathrm{h}$ of carbon leaving the system in gaseous form. The remainder of 2 to $3 \mathrm{~g} / \mathrm{h}$ still missing in the balance could not be identified.

\section{VI.B. Fuel Balance}

The total amount of deuterium retained in TEXTOR due to codeposition is estimated to be $5.6 \times 10^{22} \mathrm{D} / \mathrm{h}$ by taking into account the different contents in the various sinks of carbon. This value is of the same order of magnitude as already found earlier. ${ }^{57}$ It is $\sim 10 \%$ of the fuel rate $\left(5.5 \times 10^{23} \mathrm{D} / \mathrm{h}\right)$ introduced via the gas inlet system during the plasma pulses for the corresponding operation period (March to August 2000). Since neutral beam heating is mostly done with $\mathrm{H}$ in TEXTOR, beam fueling is neglected in a first approximation in the $\mathrm{D}$ balance. The greatest part of D is retained on the plasma-wetted surfaces of the toroidal limiter in TEXTOR.

\section{VI.C. Material Transport and Deposition in the Pump Ducts}

Sets of long-term samples (LTSs) (silicon, graphite, and INCONEL ${ }^{\circledR} 625$ targets) were distributed at the bottom of the ALT pump duct and exposed at room temperature to a total of $4.7 \mathrm{~h}$ of plasma discharges fueled with deuterium. 
The primary sources of carbon deposited in the pump ducts are the neutralizer plates, reeroded physically and chemically by deuterium, creating neutral carbon and hydrocarbon radicals. Visual inspection reveals semitransparent films along all inner areas of the pump ducts. Local variations in thickness (here related to 24-h plasma operation) strongly depend on the distance to the carbon source, i.e., the neutralizer plates. A maximal thickness of $\approx 350 \mathrm{~nm}$ appears at the position of LTS1, i.e., shifted toward the direction of the pump. Deposition rates established in the duct are extremely low, $\sim 1 \times 10^{17} \mathrm{C} / \mathrm{cm}^{2} \cdot \mathrm{h}$ in line of sight, and only $\sim 0.03 \times 10^{17} \mathrm{C} / \mathrm{cm}^{2} \cdot \mathrm{h}$ at the second LTS position nearer to the pump. ${ }^{58}$ Deposits at samples located close to the pump are not detectable. The mean carbon deposition rate within the pump ducts corresponds to $\sim 2 \%$ of carbon deposited on the neutralizer plates but only to $\sim 0.1 \%$ of carbon eroded from the toroidal belt limiter.

Carbon deposition in remote areas is also measured in situ by a commercial quartz micro balance located in the line of sight to the neutralizer at the bottom of another pump duct. The data show a fairly constant growth during daily operation and constant frequency during night and weekend breaks. A deposition rate of $\approx 30 \mathrm{~nm} / \mathrm{h}$ has been found at this location. The properties of the deposited films inside the pump ducts (and on other areas inside TEXTOR) are presented in Sec. VII.

A two-dimensional computer simulation has been applied to model the deposition pattern in the pump ducts. ${ }^{60}$ A mixture of two species in the simulation with reflection coefficients $R=0.1(90 \%)$ and $R=0.5(10 \%)$ gives the best fit with the experimental data and reasonably describes the measured thickness distribution in the ducts. In this case the total deposition efficiency is 0.97 . The remaining $3 \%$ of the incoming particles is either reflected back to the source (i.e., the neutralizer plates) and redeposited there, or they leave the system through the pump.

\section{PROPERTIES OF DEPOSITED FILMS IN TEXTOR}

Layers at the neutralizer plates are hard carbon films formed because of the codeposition with deuterium ions of several hundred electron volts $\left(T_{e} \approx 20\right.$ to $\left.50 \mathrm{eV}\right)$. The measured $\mathrm{D} / \mathrm{C}$ ratio is $\mathrm{D} / \mathrm{C} \approx 5 \times 10^{-3}$ due to high temperature excursions. ${ }^{29,60}$

Layers at sliding walls at the entrance of the pump duct region possess a slightly higher refraction index $(n \approx 1.7)$ and a fairly low D/C $<0.1$ (Ref. 60). Besides carbon and deuterium they also include an evident quantity of boron and silicon mainly originating from the neutralizer plates. ${ }^{59}$

Regarding layers built up in pump ducts, sets of samples located in one of the cold pump ducts (room temperature) in increasing distance to the neutralizer have been characterized after a total exposure time of $4.7 \mathrm{~h}$ by various analysis methods. ${ }^{58,60} \mathrm{Soft}$ polymer-like carbon films are found. They have a diffraction index $n$ between 1.6 and 1.4 , decreasing with increasing distance to the source, but a constant $\mathrm{D} / \mathrm{C}$ ratio of $\sim 0.7$. They also store a significant quantity of hydrogen $(\mathrm{H} / \mathrm{D}$ varies between 1 and 3), which may originate from water uptake. Except carbon and hydrogen isotopes, they do not contain any other elements existing in the device. Although their contribution to the total carbon balance $(0.02 \mathrm{~g} / \mathrm{h})$ is negligible, the films contain 100 to 1000 times more deuterium than the other deposits, and their uncontrolled formation in fusion devices could increase the tritium content.

Regarding layers at the liner, only a minor fraction of carbon eroded from the toroidal belt limiter $(<0.1 \%)$ has been deposited at the liner in the vicinity of this limiter. A low $\mathrm{D} / \mathrm{C}$ ratio of the deposit $(\leq 0.1)$ might not significantly influence the tritium inventory. ${ }^{29,58}$

Table I summarizes the $\mathrm{D} / \mathrm{C}$ ratio and the total deuterium content of deposited layers in TEXTOR at the various locations, including also the toroidal limiter, obstacles, and the bumper limiter. ${ }^{58}$

\section{IMPURITY TRANSPORT MODELING}

\section{VIII.A. Description of ERO-TEXTOR}

The ERO-TEXOR code is a three-dimensional MonteCarlo impurity transport code, originally based on the ERO code ${ }^{39}$ which describes the transport of physically sputtered or chemically eroded particles through the background plasma. The plasma background (especially temperature and density distribution) is needed as input from measurements or other code calculations like B2-Eirene. The incoming ion flux at each surface cell is calculated; from this, the amount of eroded particles using yields for physical and chemical erosion is determined. The eroded neutrals are followed until they are ionized or dissociated. Transport of charged particles is calculated taking into account the Lorentz force, friction due to collisions with the background plasma ions, thermal forces, and diffusion. Particles returning to wall components are redeposited or reflected and can erode new impurities. ${ }^{61}$ The ERO-TEXTOR transport code is used for different divertor configurations such as JET (Ref. 62), ITER, or ASDEX and in addition for linear plasma simulators such as PISCES and MAGNUM.

\section{VIII.B. Applications of ERO-TEXTOR: Examples}

The erosion and deposition of an originally pure tungsten test limiter is modeled for ohmic conditions in TEXTOR (Ref. 61). The surface composition in the interaction layer does not change anymore with increasing exposure time when equilibrium is reached. Areas where the carbon concentration has reached 100\% (at the edges 
TABLE I

D/C Ratio and Total Deuterium Content of Layers Deposited in TEXTOR at Different Locations

\begin{tabular}{|c|c|c|c|c|c|}
\hline $\begin{array}{c}\text { Source: } \\
\begin{array}{c}\text { Toroidal Limiter- } \\
22 \mathrm{gC} / \mathrm{h}\end{array} \\
\text { Sink }\end{array}$ & $\begin{array}{c}\text { Deposited } \\
\text { Area } \\
\left(\mathrm{m}^{2}\right)\end{array}$ & $\begin{array}{c}\text { Average } \\
\text { Temperature } \\
\left({ }^{\circ} \mathrm{C}\right)\end{array}$ & $\begin{array}{c}\text { Deposited } \\
\text { Carbon } \\
(\mathrm{g} / \mathrm{h})\end{array}$ & $\begin{array}{c}\text { Deuterium } \\
\text { Content } \\
\text { D/C }\end{array}$ & $\begin{array}{c}\text { Codeposited } \\
\text { Deuterium } \\
\left(10^{20} / \mathrm{h}\right)\end{array}$ \\
\hline $\begin{array}{l}\text { Toroidal limiter } \\
\text { SOL obstacles } \\
\text { Liner } \\
\text { Bumper limiter } \\
\text { Neutralizer plates } \\
\text { Pump ducts } \\
\text { Pumped out } \\
\text { Total content }\end{array}$ & $\begin{array}{l}1.1 \\
0.2 \\
32 \\
6 \\
0.08 \\
1.4\end{array}$ & $\begin{array}{c}350 \\
\text { Excursions } \\
150 \text { to } 350 \\
150 \text { to } 350 \\
150 \text { to } 350 \\
25 \\
25\end{array}$ & $\begin{array}{c}10 \\
6 \\
<4 \times 10^{-4} \\
1 \\
1 \\
0.02 \\
1 \text { to } 2 \\
19 \text { to } 20\end{array}$ & $\begin{array}{c}0.1 \\
4 \times 10^{-4} \\
0.1 \\
0.1 \\
5 \times 10^{-3} \\
0.7 \\
-\end{array}$ & $\begin{array}{c}500 \\
1.2 \\
\text { Negligible } \\
50 \\
2.5 \\
7 \\
- \\
561\end{array}$ \\
\hline
\end{tabular}

of the limiter) are net deposition zones, where a carbon layer is built up continuously with increasing exposure time. At locations with lower carbon concentration $(<100 \%)$, the incoming carbon flux is in balance with the outgoing carbon flux, and only the tungsten in these regions suffers from continuous erosion. The buildup of net deposition zones at the toroidal edges and a net erosion zone in the middle part of the limiter surface is in agreement with experimental observations.

The simulated and measured radial profiles of the WI emission are in good agreement. The simulated CII profile consists of two parts: One is from sputtered car- bon, and the other is from carbon ions from the background plasma reflected at the limiter surface (as neutrals), which contribute to the CII profile deeper in the plasma. Simulated and measured profiles are in fair agreement.

The transport of methane molecules chemically released from a graphite limiter in the SOL of TEXTOR is modeled ${ }^{63}$ using measured radial decays of $T_{e, i}$ and $n_{e}$. Sticking of hydrocarbons hitting the surface is assumed to be zero, and rate coefficients are taken first from Ehrhardt-Langer ${ }^{43}$ but compared with recent data from Brooks et al. ${ }^{64}$ for electron reactions and from Janev et al. ${ }^{46}$ for proton reactions.

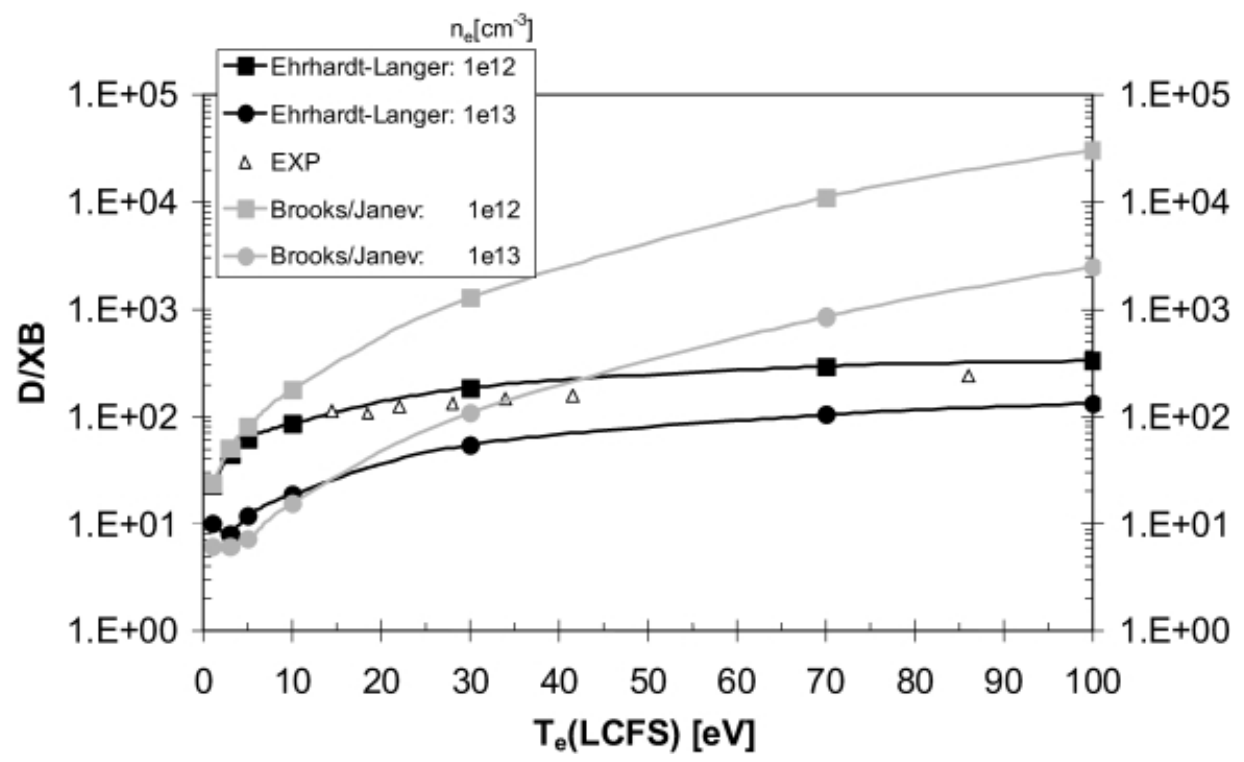

Fig. 9. Modeled D/XB for $\mathrm{CD}$ from $\mathrm{CD}_{4}$ as a result of chemically eroded $\mathrm{CD}_{4}$ at a TEXTOR test limiter in dependence on $T_{e}$ and $n_{e}$ : Ehrhardt-Langer data versus Brooks/Janev data. Measured data from TEXTOR are included for comparison. 
Figure 9 shows the modeled D/XB values for different electron temperatures and two different electron densities. With the Brooks/Janev data, the eroded methane molecules return to the test limiter preferentially in the form of a hydrocarbon due to low rate coefficients at high plasma temperatures. The probability to reach the $\mathrm{CD}$ radical decreases, which leads to significant higher $\mathrm{D} / \mathrm{XB}$ values at high plasma temperatures. Modeled $\mathrm{D} / \mathrm{XB}$ values are up to a factor of 100 higher compared with the few experimental data, whereas the use of the Ehrhardt-Langer data gives better agreement. At smaller temperatures the difference between the simulated D/XB values using Ehrhardt-Langer or Brooks/Janev data decreases and is negligible at temperatures $<5 \mathrm{eV}$.

The preferential carbon deposition at the louvers of the inner divertor of JET MkIIA cannot be reproduced by ERO-JET for "standard" assumptions for the sticking of hydrocarbons and the reerosion of deposits. ${ }^{62} \mathrm{Sim}-$ ilar to the modeling of injected ${ }^{13} \mathrm{CH}_{4}$ at TEXTOR (Sec. IV), the hydrocarbon transport can be understood in terms of enhanced reerosion of deposited carbon layers. Coupling of the ERO-JET code with the Redep code, which deals in detail with the carbon transport inside the louver region, gives an improved understanding and further emphasizes the effect of enhanced reerosion of deposits. ${ }^{65}$

The two-dimensional distribution of the CIII line emission pattern in the divertor MkIIGB can be reproduced by ERO-JET. The inner CIII light is detached from the divertor plates, whereas the outer one is attached, which is explained by the higher temperatures in the outer divertor. A parameter study for MkIIA was carried out to analyze the influence of the plasma parameter and the location of hydrocarbon injection on the derived $\mathrm{D} / \mathrm{XB}$ values. The modeling shows a significant dependence of $\mathrm{D} / \mathrm{XB}$ on the location of injection. Injection at the strike point leads to a decreasing $\mathrm{D} / \mathrm{XB}$ with increasing flux, whereas injection at the center of the base plate in the private flux region (PFR) gives the opposite behavior. Moreover, injection at the strike point gives $\mathrm{D} / \mathrm{XB}$ values between 2 and 16 whereby injection at the center of the base plate in the PFR gives much higher values (up to 2000) especially at higher fluxes. This reflects the completely different plasmas into which the methane is puffed. The SOL plasma is extremely cold and thin, whereas near the strike point, we have high temperatures and densities. These calculations demonstrate the importance of the puffing location for the derived $\mathrm{D} / \mathrm{XB}$ values.

Recently, JET injection experiments using various locations of injection and sweeping the strike point also indicate a strong dependence of the measured $\mathrm{D} / \mathrm{XB}$ on the puffing location. In the ERO-ITER calculations, ${ }^{66}$ two-dimensional plasma parameters are taken from B2Eirene for the reference case 345 . The sticking of hydrocarbons $S$ is assumed to be either zero or one to claim two boundary assumptions; chemical erosion is assumed to be $2 \%$. Zero sticking $S=0$ leads to a redeposition prob- ability on the target plates of $\sim 86 \%$ and a net erosion peak of $15 \mathrm{~nm} / \mathrm{s}$ near the strike point. The assumption of $S=1$ leads to an increased redeposition of $\sim 95 \%$ and a decreased erosion peak of $8 \mathrm{~nm} / \mathrm{s}$. Particles not redeposited on the divertor plate are lost in the private flux region-mainly as neutrals. With a $\mathrm{T} / \mathrm{T}+\mathrm{C}$ ratio of 0.5 , chemical erosion of $2 \%$ for the inner and outer divertors and $S=0$, a total codeposition rate of tritium of $6 \mathrm{mg} / \mathrm{s}$ trapped in remote areas is estimated. The safety limit (licensing) of $350 \mathrm{~g}$ tritium would then be reached after about 150 discharges of 400-s duration. With $S=1$ the tritium retention decreases by a factor of $\sim 3$. In the current calculations no material flux from the main chamber is considered, and under those conditions the lifetime of the inner target plate (peak erosion at the outer divertor is slightly lower) can be estimated to $\sim 625$ ITER discharges assuming a maximum tolerable erosion of $0.5 \mathrm{~cm}$. This is less critical than the tritium retention and will be even much more relaxed if Be deposition from the main chamber is taken into account.

\section{CONCLUSION}

The investigation of erosion processes in TEXTOR and laboratory experiments have led to an improved knowledge of the parameter dependencies, which are important for future fusion experiments. This concerns, e.g., the decrease of chemical erosion of carbon at elevated surface temperatures and high fluxes and the increase due to synergistic effects by simultaneous bombarding with ions. RES of graphite at surface temperatures $>1300 \mathrm{~K}$ was observed in ion beam laboratory experiments but so far not in the TEXTOR tokamak and therefore seems not to be a critical issue for future fusion machines. The physical sputtering of high- $Z$ elements like tungsten and their prompt redeposition are well understood. The accumulation of eroded high- $Z$ particles in the core plasma has been analyzed in detail and explained by transport models. This delivers critical values for various parameters (like density or heating power) for preventing instabilities caused by high- $Z$ accumulation.

Studies of the transport of externally injected molecules $\left({ }^{13} \mathrm{CH}_{4}\right.$ and $\left.\mathrm{SiH}_{4}\right)$, which are used as markers, gave new insight into the edge transport of molecules. This technique later was adopted in other fusion experiments like JET, ASDEX, and DIII-D. It could be concluded that redeposited carbon layers at plasma-wetted areas suffer from enhanced reerosion. Depending on the experimental geometry, this can lead to a long-range transport of carbon via successive redeposition and reerosion to remote areas. In the case of ITER, one can expect the main tritium retention in remote areas (shadowed regions or gaps) for which special cleaning methods have to be developed. 
TEXTOR is the first device for which a detailed carbon and fuel balance has been done. It can be concluded that the carbon transport is too strong to be tolerated in a machine like ITER, with the limiting factor being the codeposition of tritium. New insights into the short- and long-range transport of carbon and the properties of the deposited layers have been obtained. Analysis of the deposits in the pump ducts leads to the conclusion of high sticking properties for hydrocarbons in shadowed areas, consistent with observations in other devices.

\section{REFERENCES}

1. G. FEDERICI et al., "Key ITER Plasma Edge and PlasmaMaterial Interaction Issues," J. Nucl. Mater., 313-316, 11 (2003).

2. E. VIETZKE, and A. A. HAASZ, "Chemical Erosion," Physical Processes of the Interaction of Fusion Plasmas with Solids, p. 135, W. HOFER and J. ROTH, Eds., Academic Press (1996).

3. E. VIETZKE, K. FLASKAMP, and V. PHILIPPS, "Hydrocarbon Formation in the Reaction of Atomic Hydrogen with Pyrolytic Graphite and the Synergistic Effect of Argon Ion Bombardment," J. Nucl. Mater., 111+112, 763 (1982).

4. E. VIETZKE, V. PHILIPPS, and K. FLASKAMP, "Chemical Reactivity of Atomic Hydrogen on Graphite Pre-Irradiated by Hydrogen and Argon Ions," J. Nucl. Mater., 162-164, 898 (1989).

5. A. SCHENK et al., "Mechanism of Chemical Erosion of SputterDeposited C:H Films," Appl. Phys. Lett., 61, 2414 (1992).

6. E. VIETZKE, K. FLASKAMP, V. PHILIPPS, G. ESSER, and P. WIENHOLD, and J. WINTER, "Chemical Erosion of Amorphous Hydrogenated Carbon Films by Atomic and Energetic Hydrogen," J. Nucl. Mater., 145-147, 443 (1987).

7. E. VIETZKE, and V. PHILIPPS, "Surface Modification Due to Hydrogen-Graphite Interaction," Nucl. Instrum. Methods B, 23, 449 (1987).

8. E. VIETZKE, "Energy Distributions of $\mathrm{CD}_{4}$ and $\mathrm{CD}_{3}$ Chemically Released from Graphite by $\mathrm{D}^{+}$and $\mathrm{D}^{0} / \mathrm{Ne}^{+}$Impact," J. Nucl. Mater., 290-293, 158 (2001).

9. S. BREZINSEK et al., "Chemical Erosion Measurements in Tokamaks by Spectroscopy," Phys. Scripta, T111, 42 (2004).

10. A. POSPIESZCZYK et al., "Chemical Erosion Measurements from Various Carbon Based Limiters and Coatings from TEXTOR-94," J. Nucl. Mater., 241-243, 833 (1997).

11. J. ROTH, "Chemical Erosion of Carbon Based Materials," J. Nucl. Mater., 266-269, 51 (1999).

12. B. SCHWEER et al., "Limiter Lock Systems at TEXTOR: Flexible Tools for Plasma-Wall Investigation," Fusion Sci. Technol., 47, 138 (205).

13. V. PHILIPPS, E. VIETZKE, and M. ERDWEG, "In-Situ Observation of the Chemical Erosion of Graphite in the Scrape-Off-Layer of TEXTOR," J. Nucl. Mater., 162-164, 550 (1989).

14. J. ROTH et al., "Flux Dependence of Chemical Erosion and Its Implications for ITER," presented at 16th Int. Conf. Plasma Surface Interactions in Controlled Fusion Devices, Portland, Maine, 2004.

15. E. VIETZKE, T. TANABE, V. PHILIPPS, M. ERDWEG, and K. FLASKAMP, "The Reaction of Energetic $\mathrm{O}_{2}^{+}$Thermal $\mathrm{O}_{2}$ and Thermal $\mathrm{O}_{2} / \mathrm{Ar}^{+}$on Graphite and the Use of Graphite for Oxygen Collector Probes," J. Nucl. Mater., 145-147, 425 (1987).
16. A. REFKE, V. PHILIPPS, M. ERDWEG, E. VIETZKE, and J. VON SEGGERN, "Interaction of Energetic Oxygen with Different Boron/Carbon Materials,” J. Nucl. Mater., 212-215, 1255 (1994).

17. E. VIETZKE, A. REFKE, V. PHILIPPS, and M. HENNES, "Energy Distribution of the Reaction Products from Graphite and $\mathrm{B}_{4} \mathrm{C}$ During Energetic Oxygen Impact," J. Nucl. Mater., 220-222, 249 (1995).

18. M. WADA et al., "High Heat Flux Exposure-Experiments of a Tungsten Test Limiter at TEXTOR-94," J. Nucl. Mater., 258-263, 853 (1998).

19. J. ROTH, J. B. ROBERTO, and K. L. WILSON, "Enhanced Sputtering of Graphite at High Temperature," J. Nucl. Mater., 123, 1-3, 1447 (1984).

20. V. PHILIPPS, K. FLASKAMP, and E. VIETZKE, "Enhancement of the Sputtering Yield of Pyrolytic Graphite at Elevated Temperatures," J. Nucl. Mater., 111 \& 112, 781 (1982).

21. V. PHILIPPS, E. VIETZKE, and H. TRINKAUS, "Radiation Enhanced Sublimation of Carbon and Carbon Related Materials," J. Nucl. Mater., 179-181, 25 (1991).

22. V. PHILIPPS, A. POSPIESZCZYK, B. SCHWEER, B. UNTERBERG, E. VIETZKE, and H. TRINKAUS, "Investigation of Radiation Enhanced Sublimation of Graphite Test-Limiters in TEXTOR," J. Nucl. Mater., 220-222, 467 (1995).

23. N. NODA, R. NEU, and V. PHILIPPS, "A Review of Recent Experiments on $\mathrm{W}$ and High Z Materials as Plasma-Facing Components in Magnetic Fusion Devices," J. Nucl. Mater., 241-243, 227 (1997).

24. J. RAPP et al., "Transport Studies of High-Z Elements in Neon Edge Radiation Cooled Discharges in TEXTOR-94," Plasma Phys. Control. Fusion, 39, 1615 (1997).

25. V. PHILIPPS et al., "Experiments with Tungsten Limiters in TEXTOR-94," J. Nucl. Mater., 258-263, 858 (1998).

26. D. NAUJOKS and R. BEHRISCH, "Erosion and Redeposition at the Vessel Walls in Fusion Devices," J. Nucl. Mater., 220-222, 227 (1995).

27. G. FUSSMANN et al., "High-Z Elements as Target Materials in Fusion Devices," Proc. 15th Int. Symp. Plasma Physics and Controlled Nuclear Fusion Research, Vol. 2, p. 143 (1995).

28. M. RUBEL et al., "Impact of Molybdenum and Tungsten Limiters on Ion Fluxes in the Plasma Edge of TEXTOR," J. Nucl. Mater., 249, 116 (1997).

29. P. WIENHOLD et al., "Short and Long Range Transport of Materials Eroded from Wall Components in Fusion Devices," J. Nucl. Mater., 313-316, 311 (2003).

30. M. TOKAR et al., "Nature of High Z Impurity Accumulation in Tokamaks," Nucl. Fusion, 37, 12 (1997).

31. R. T. McGRATH, B. L. DOYLE, J. N. BROOKS, A. E. PONTAU, and G. J. THOMAS, "Impurity Deposition on ALT-1 Limiter Heads," J. Nucl. Mater., 145-147, 660 (1987).

32. J. N. BROOKS, "Modeling and Analysis of Erosion and Redeposition for Limiter and Divertor Impurity Control Systems," Nucl. Tech./ Fusion, 4, 33 (1983).

33. T. HIRAI et al., "Deuterium Release and Microstructure of Tantalum-Tungsten Twin Limiters Exposed in TEXTOR-94," J. Nucl. Mater., 307-311, 79 (2002).

34. M. WADA et al., "Inhomogeneous Heat Loading to High-Z Test Limiters Depending upon the Limiter Materials," J. Nucl. Mater., 313-316, 292 (2003).

35. M. RUBEL et al., "An Overview of Fuel Inventory in Tungsten and Composite Limiters," J. Nucl. Mater., 307-311, 111 (2002). 
36. T. TANABE et al., "Material Mixing on W/C Twin Limiter in TEXTOR-94," Fusion Eng. Des., 49 \& 50, 355 (2000).

37. T. HIRAI et al., "Testing of Tungsten and Tantalum Limiters in the TEXTOR Tokamak: Material Performance and Deuterium Retention," Physi. Scripta, T103, 59 (2003).

38. M. RUBEL et al., "Graphite-Tungsten Twin Limiters in Studies of Material Mixing Processes on High Heat Flux Components," J. Nucl. Mater., 283-287, 1089 (2000).

39. D. NAUJOKS, R. BEHRISCH, J. P. COAD, and L. C. J. M. DE KOCK, "Material Transport by Erosion and Redeposition on Surface Probes in The Scrape-Off Layer of JET," Nucl. Fusion, 33, 581 (1993).

40. P. WIENHOLD, F. WESCHENFELDER, P. KARDUCK, K. OHYA, S. RICHTER, M. RUBEL, and J. VON SEGGERN, "NonUniform Carbon Redeposition on Graphite," J. Nucl. Mater., 266269, 986 (1999).

41. P. WIENHOLD, F. WESCHENFELDER, and J. WINTER, "Colorimetry of Interference Colours to Investigate Thickness Changes of Protective Coatings in TEXTOR," Nucl. Instrum. Methods in Phys. Res. B, 94, 503 (1994).

42. P. WIENHOLD et al., "Carbon Transport in TEXTOR-94. Aspects of Long Term Operation,” J. Plasma Fusion Res., 3, 297 (2000).

43. A. B. EHRHARDT and W. D. LANGER, "Collisional Processes of Hydrocarbons in Hydrogen Plasmas," PPPL-2477, Princeton Plasma Physics Laboratory (1987).

44. E. VIETZKE, V. PHILIPPS, F. FLASKAMP, and C. WILD, "The Reaction of Atomic Hydrogen with Plasma Deposited a-C:H Films," Les Editions de Physique, XVII, 351 (June 1987).

45. R. K. JANEV and D. REITER, "Collisional Processes of Hydrocarbon Species in Hydrogen Plasmas: i) The Methane Family," Report Jül-3966 (2002).

46. R. K. JANEV, J. G. WANG, and T. KATO, "Cross Sections and Rate Coefficients for Charge Exchange Reactions of Protons with Hydrocarbon Molecules," NIFS-DATA-64, National Institute for Fusion Science (2001).

47. J. LIKONEN et al., "Studies of Impurity Deposition/Implantation in JET Divertor Tiles Using SIMS and Ion Beam Techniques," Fusion Eng. Des., 66-68, 219 (2003).

48. G. F. MATTHEWS, "Material Migration in Divertor Tokamaks," presented at 16th Int. Conf. Plasma Surface Interactions in Controlled Fusion Devices, Portland, Maine, 2004.

49. S. L. ALLEN et al., " ${ }^{13} \mathrm{C}$ Transport Studies in L-Mode Divertor Plasma on DIII-D," presented at 16th Int. Conf. Plasma Surface Interactions in Controlled Fusion Devices, Portland, Maine, 2004.

50. V. ROHDE et al., "Carbon Erosion and a-C:H Layer Formation at ASDEX Upgrade," presented at 16th Int. Conf. Plasma Surface Interactions in Controlled Fusion Devices, Portland, Maine, 2004.

51. U. KÖGLER et al., "Studies on Plasma Edge Transport and Layer Deposition by Local Gas Injection," J. Nucl. Mater., 241-243, 816 (1997).
52. PH. MERTENS and M. SILZ, "Most Recent Results from LaserInduced Fluorescence on TEXTOR- 94: Atomic Silicon," Proc. 7th Symp. Laser-Aided Plasma Diag. LAPD-7, Fukuoka, Japan, 150 (1995).

53. A. HUBER et al., "Behaviour of Silicon Doped CFC Limiter under High Heat Load in TEXTOR," Phys. Scripta, T91, 61 (2001).

54. S. KÖTTER et al., "Development of Thick $\mathrm{B}_{4} \mathrm{C}$ Coatings for the First Wall of W7-X," Phys. Scripta, T91, 117 (2001).

55. A. HUBER et al., "Spectroscopic Observation of SiI- and SiII Emission Lines in the Boundary of TEXTOR and Comparison with Kinetic Calculations," Plasma Phys. Control. Fusion, 45, 89 (2003).

56. A. POSPIESZCZYK et al., " $\mathrm{B}_{4} \mathrm{C}$-Limiter Experiments at TEXTOR,” J. Nucl. Mater., 313-316, 223 (2003).

57. M. MAYER, V. PHILIPPS, P. WIENHOLD, H. G. ESSER, J. VON SEGGERN, and M. RUBEL, "Hydrogen Inventories in Nuclear Fusion Devices," J. Nucl. Mater., 290-293, 381 (2001).

58. J. VON SEGGERN, P. WIENHOLD, T. HIRAI, V. PHILIPPS, and H. G. ESSER, "Long Term Behaviour of Material Erosion and Deposition on the Vessel Wall and Remote Areas of TEXTOR," J. Nucl. Mater., 313-316, 439 (2003).

59. M. RUBEL et al., "Thick Co-Deposits and Dust in Controlled Fusion Devices with Carbon Walls: Fuel Inventory and Growth Rate of Co-Deposited Layers," Phys. Scripta, T103, 20 (2003).

60. J. VON SEGGERN, A. KIRSCHNER, V. PHILIPPS, and P. WIENHOLD, "Deposition of Hydrogen Rich Carbon Films in Pump Ducts of TEXTOR," Phys. Scripta, T111, 118 (2004).

61. A. KIRSCHNER, V. PHILIPPS, J. WINTER, and U. KÖGLER, "Simulation of the Plasma-Wall-Interaction in a Tokamak with the Monte-Carlo Code ERO-TEXTOR," Nucl. Fusion, 40, 5, 989 (2000).

62. A. KIRSCHNER et al., "Hydrocarbon Transport in the MkIIa Divertor of JET," Plasma Phys. Control. Fusion, 45, 309 (2003).

63. A. KIRSCHNER, V. PHILIPPS, A. POSPIESZCZYK, and P. WIENHOLD, "Monte-Carlo Simulations of Chemical Erosion in TEXTOR-94 with the ERO-TEXTOR Code," Phys. Scripta, T91, 57 (2001).

64. J. N. BROOKS, Z. WANG, D. N. RUZIC, and D. A. ALMAN, "Hydrocarbon Rate Coefficients for Proton and Electron Impact Ionisation, Dissociation, and Recombination in a Hydrogen Plasma," ANL/ FTP/TM-297, Argonne National Laboratory (1999).

65. J. N. BROOKS, A. KIRSCHNER, D. G. WHYTE, D. N. RUZIC, and D. A. ALMAN, "Advances in Modelling of Chemical Erosion/ Redeposition of Carbon Divertors and Application to the JET Tritium Codeposition Problem," J. Nucl. Mater., 313-316, 424 (2003).

66. A. KIRSCHNER et al., "Modelling of the Erosion and Redeposition Behaviour in Present Fusion Devices and Extrapolations to ITER," Proc. 30th European Physical Society Conf. St., Petersburg, Russia, 2003, Europhysics Conference Abstracts, Vol. 27A, P-3.196. 